\title{
Potential association between the recent increase in campylobacteriosis incidence in the Netherlands and proton-pump inhibitor use - an ecological study
}

M Bouwknegt (martijn.bouwknegt@rivm.nl) ${ }^{1}$, W van Pelt ${ }^{1}$, M E Kubbinga $^{1}$, M Weda ${ }^{1}$, A H Havelaar ${ }^{1,2}$

1. National Institute for Public Health and the Environment, Bilthoven, The Netherlands

2. Utrecht University, Utrecht, the Netherlands

The Netherlands saw an unexplained increase in campylobacteriosis incidence between 2003 and 2011, following a period of continuous decrease. We conducted an ecological study and found a statistical association between campylobacteriosis incidence and the annual number of prescriptions for proton pump inhibitors (PPIs), controlling for the patient's age, fresh and frozen chicken purchases (with or without correction for campylobacter prevalence in fresh poultry meat). The effect of PPIs was larger in the young than in the elderly. However, the counterfactual population-attributable fraction for PPIs was largest for the elderly (ca $45 \%$ in 2011) and increased at population level from $8 \%$ in 2004 to $27 \%$ in 2011 . Using the regression model and updated covariate values, we predicted a trend break for 2012, largely due to a decreased number of PPI prescriptions, that was subsequently confirmed by surveillance data. Although causality was not shown, the biological mechanism, age effect and trend-break prediction suggest a substantial impact of PPI use on campylobacteriosis incidence in the Netherlands. We chose the ecological study design to pilot whether it is worthwhile to further pursue the effect of PPI on campylobacteriosis and other gastrointestinal pathogens in prospective cohort studies. We now provide strong arguments to do so.

\section{Introduction}

Gastric acid is a first barrier against exogenous bacteria. The acid is secreted by parietal cells to maintain a median gastric pH of around 1.4 [1]. This level is generally sufficiently low to inactivate bacteria when the passage time is short (i.e. when the bacterial adaptive acid-tolerance response has not started), whereas $\mathrm{pH}$ levels $>4$ substantially increase their probability of survival $[2,3]$. Proton pump inhibitors (PPIs) are used to increase gastric $\mathrm{pH}$ in patients requiring, for example, treatment of gastro-oesophageal reflux disease and treatment or prevention of gastric and duodenal ulcers (e.g. co-prescribed with analgesics such as nonsteroidal anti-inflammatory drugs). PPI use is therefore hypothesised to facilitate gastrointestinal infections and has been reported repeatedly in casecontrol studies as a risk factor for Campylobacter and Salmonella infections with odds ratios between 3.5 and 12, suggesting a substantially increased risk [4]. The estimated attributable fraction for PPI use in campylobacteriosis cases was estimated at $8 \%$ in a Dutch case-control study [5].

Several European countries such as the Netherlands, Norway and the United Kingdom, experienced decreasing campylobacteriosis incidence rates from 2001 onwards, but faced a subsequent increase starting between 2003 and 2008. Simultaneously, other European countries, such as Denmark and Iceland, did not observe such an increase. In these countries, measures to reduce exposure of consumers to chicken meat are thought to have contributed to the favourable trends $[6,7]$. The decreasing incidence in the Netherlands, based on culture-positive campylobacteriosis cases, continued until 2003, followed by an increasing trend until 2011. This increase cannot be explained by improved detection methods and/or changes in testing regime, (data not shown). Furthermore, Campylobacter contamination of chicken fillets at retail, a recognised risk factor for Campylobacter infection, showed a decreasing trend between 2002 and 2011 in the Netherlands [8]. Anecdotal reports suggested that the use of PPIs in the Netherlands had increased in the years before 2011. We therefore hypothesise that the increase in campylobacteriosis cases in the Netherlands is, at least in part, related to increased PPI use. To study this hypothesis we related national trends in PPI prescriptions to the annual number of reported campylobacteriosis cases between 2004 and 2011, while controlling for age and chicken consumption. We then estimated the proportional incidence that was potentially related to PPI use. 
Annual number of prescribed proton pump inhibitors at pharmacies and annual incidence of reported and estimated (with the regression model) campylobacteriosis cases, the Netherlands, 2004-2012

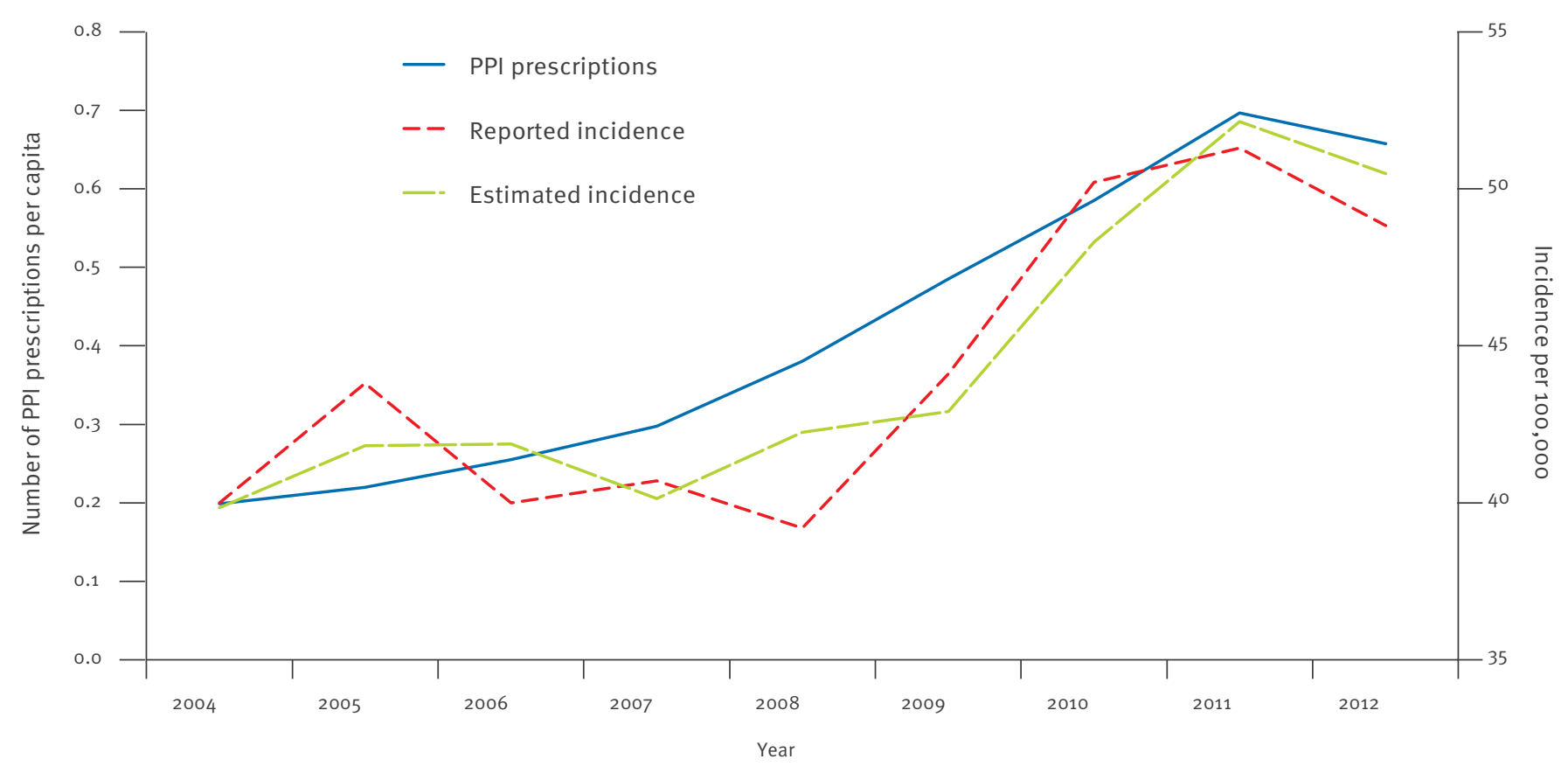

PPI: proton pump inhibitor.

\section{Data and analysis}

Data on PPI prescriptions were collected at Anatomical Therapeutic Chemical (ATC) level 5 (according to the World Health Organization (WHO) classification for medicine) from annual reports of the Foundation for Pharmaceutical Statistics (SFK) in the Netherlands (available in Dutch at www.sfk.nl) covering 95\% of Dutch pharmacies. These reports cover drugs prescribed by general practitioners and physicians, and exclude over-the-counter sales. Data were available for the two most frequently prescribed PPIs: omeprazole and pantoprazole. For the former, prescription data were available for the whole study period. For the latter, prescription counts were available from 2005 onwards. The number for 2004 was estimated by dividing the available annual sales revenue for the drug (which was available) by the unit price calculated for 2005 . Given the similar mode of action of the two drugs, the prescription numbers for both PPIs were aggregated. The age distribution of patients receiving PPI prescriptions was not available from the annual reports. Age-stratified data were available at ATC-4 level from Statistics Netherlands [9] for the period 2006 to 2011, covering more generally use of medicine to suppress peptic ulcers and gastro-oesophageal reflux (ATC-code A02B). These data reflected medicine refunded by 10 (groups of) health insurance companies covering $>90 \%$ of the Dutch population.

Four age groups were considered: $0-25,26-50,51-70$ and $\geq 71$ years. Data on national sales of fresh and frozen chicken were provided by the Product Boards for Livestock, Meat and Eggs and used as a proxy for consumption. To indicate exposure, sales of fresh chicken were multiplied with the annual prevalence of campylobacter in fresh chicken meat as estimated from monitoring at retail [8]. Sales data were stratified for the consumers' age based on the population size per age group. The population size per age group per year was obtained from Statistics Netherlands [10]. Annual incidences for reported campylobacteriosis cases, including the cases' age, were obtained for the period 2004 to 2012 from national laboratory surveillance data covering $52 \%$ of the Dutch population [11].

Negative binomial regression was used to relate reported campylobacter case numbers per age group (dependent variable) to the independent variables PPI prescriptions, age and chicken consumption (fresh and frozen). The age-stratified population size was used as offset. Data from 2004 to 2011 were used; not all data were available for earlier years. Backward elimination of variables was done until all remaining factors were significantly associated with campylobacteriosis cases at the $95 \%$ confidence level. Two-way and three-way interaction terms were subsequently examined for statistical significance at the same level.

The excess incidence due to PPI prescriptions expressed as population-attributable fraction (PAF) was estimated by counterfactual assessment [12]. The regression parameters and their covariance were used 
Negative binomial regression analysis for association of factors with the reported campylobacteriosis incidence, the Netherlands, 2004-2011

\begin{tabular}{|l|c|c|c|c|}
\multirow{2}{*}{ Variable } & \multirow{2}{*}{ Class } & \multicolumn{2}{|c|}{ IRR } & \multirow{2}{*}{ p value } \\
\cline { 2 - 4 } & & Most likely & $95 \% \mathrm{Cl}$ & \\
\hline \multirow{3}{*}{ Age (years) } & $0-25$ & 1.00 & - & \multirow{2}{*}{0.0001} \\
\cline { 2 - 4 } & $26-50$ & 0.65 & $0.57-0.74$ & \\
\cline { 2 - 4 } & $51-70$ & 0.59 & $0.51-0.67$ & \\
\cline { 2 - 4 } & $\geq 71$ & 0.56 & $0.48-0.65$ & \\
\hline \multirow{3}{*}{$\begin{array}{l}\text { PPI per capita } \\
\text { (per unit } \\
\text { increase) }\end{array}$} & $0-25$ & 2.14 & $0.99-4.64$ & \multirow{2}{*}{0.0001} \\
\cline { 2 - 4 } & $26-50$ & 1.81 & $1.24-2.65$ & \\
\cline { 2 - 4 } & $51-70$ & 1.69 & $1.46-1.97$ & \multirow{2}{*}{0.0032} \\
\cline { 2 - 4 } & $\geq 71$ & 1.33 & $1.20-1.47$ & \\
\hline $\begin{array}{l}\text { Frozen chicken } \\
\text { purchase }\end{array}$ & $\begin{array}{c}\text { Per } 10^{6} \mathrm{~kg} \\
\text { increase }\end{array}$ & 0.95 & $0.92-0.98$ & \multirow{2}{*}{0.0032} \\
\hline
\end{tabular}

$\mathrm{Cl}$ : confidence interval; PPI: proton pump inhibitor; IRR: incidence rate ratio.

a The effect of PPI-prescriptions on the incidence was modified by age $(p=0.04)$

to estimate the number of campylobacteriosis cases per age group per year, setting the number of PPI prescriptions to zero. The difference was divided by the estimated number of cases based on the collected data to obtain the PAF.

Data for 2012 for the independent variables of the final model (i.e. PPI per capita, chicken purchases and population counts per age group) were used to predict the number of campylobacteriosis cases for 2012 using the regression parameters and their covariance. This number was subsequently compared to the case numbers reported for $\mathbf{2 0 1 2}$ to the National Institute for Public Health and the Environment (Rijksinstituut voor Volksgezondheid en Milieu; RIVM) through the laboratory surveillance.

\section{Results}

The number of prescribed PPI in the Netherlands has increased since 2004 (Figure 1), especially in the older age groups. Campylobacteriosis incidence has increased since 2003 (Figure 1).

The trend and yearly fluctuations in the number of campylobacteriosis cases were explained statistically by PPI prescriptions ( $p<0.0001)$, age ( $p<0.0001)$, the interaction between age and PPI prescriptions ( $p<0.04$ ), and consumption of frozen chicken meat (preventive factor; $p=0.003$ ) (Table).

Consumption of fresh chicken adjusted for Campylobacter contamination at retail was not significantly associated with the campylobacteriosis incidence $(p=0.19)$. The effect of PPI prescriptions was largest for the younger age groups and gradually decreased for older ages (Figure 2). The estimated counterfactual attributable proportion for PPI prescriptions was $8 \%$ (95\% confidence interval (Cl): $0-16$ ) in 2004 and increased continuously to $27 \%$ ( $95 \% \mathrm{Cl}: 30-34$ ) in 2011. The estimated proportion differed by age group: $12 \%$ (95\% Cl: 5-19) for the youngest group, $24 \%$ (95\% $\mathrm{Cl}: 15-32)$ for ages $26-50$ years, $45 \%(95 \% \mathrm{Cl}: 39-51)$ for ages $51-70$ years and $41 \%(95 \% \mathrm{Cl}: 34-48)$ for the oldest age group. That the attributable proportion for the elderly was higher despite the lower effect size per PPI prescription compared with the young, results from the larger number of prescriptions in the older groups.

The number of prescribed PPI declined in 2012 compared with 2011, most likely because of changes in refunding policies. In total our model predicted 8,400 (95\% Cl: 7,600-9,100) cases of campylobacteriosis in 2012, a mean decrease of 230 cases from 2011. In accordance with the prediction, the number of reported campylobacteriosis cases decreased by approximately 320 to 8,200 in 2012.

\section{Discussion}

The current study was set up as an ecological study to generate hypotheses based on data that were available at an aggregate level. Ecological associations often fail to reflect the biological effect on the individual, and the aggregation of data undermines the control of confounding [13]. Proper data to analyse causal associations were, however, not available. Collecting such data would have required extensive time and funding, which we did not have at the time of our study. We therefore chose the approach of an ecological study to examine whether it is worthwhile to pursue studies on the effect of PPI on campylobacteriosis further. As such, we are unable to conclude on causality between PPI prescriptions and Campylobacter infections. Nevertheless, a number of arguments favour a causal association. Firstly, the biological rationale for the observed effect is plausible: gastric acid secretion is impaired structurally by PPI use, leading to an increased gastric $\mathrm{pH}$ that favours pathogen survival. Secondly, the age modification of the PPI effect can be explained biologically. Gastric acid secretion in the elderly appears to be impaired compared with younger individuals due to e.g. atrophic gastritis $[14,15]$, resulting in a slower return to baseline levels after $\mathrm{pH}$-level disruption [16], and probably in an increased probability of pathogen passage to the intestines [17]. The effect of PPI prescriptions on this probability may therefore be smaller than in younger age groups. Thirdly, the model pre-

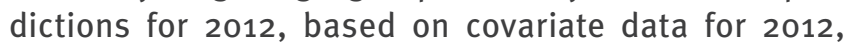
suggested a trend break, which was confirmed by surveillance data. Lastly, the current study estimated that $8 \%$ of the reported campylobacteriosis cases in 2004 were caused by PPI prescriptions. Our estimate for 2004 is similar to the estimated population-attributable fraction for PPI use of $8 \%$ in an independent casecontrol study on Campylobacter in the Netherlands that was based on data collected in 2003 at the individual level [5]. 
Effect of the number of prescribed proton pump inhibitors per capita per age group on the campylobacteriosis incidence, the Netherlands, 2004-2011

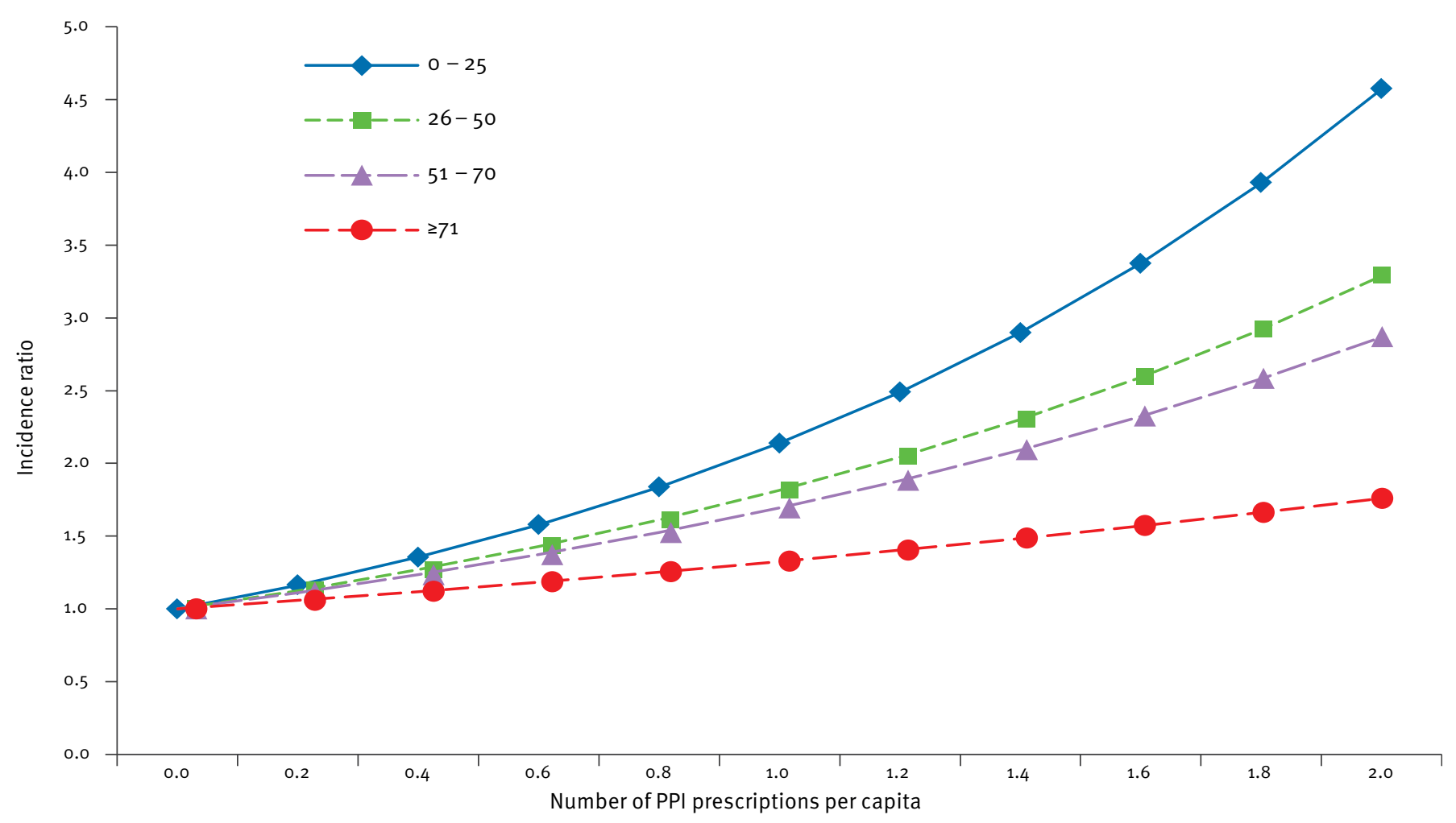

PPI: proton pump inhibitor.

The findings in the current study are similar to those obtained by Strachan et al. [18] for Scotland. These authors found a consistent association between reported campylobacteriosis cases and PPI use between 1990 and 2011. The attributable fraction was largest for those aged over 65 years, reaching more than $30 \%$ in the period 2007 to 2011 , which is comparable to our average estimate of ca $35 \%$ in that period. Brophy et al. [19] recently showed an increased risk of PPI use for acquiring campylobacteriosis (hazard ratio 1.5) at individual level. However, they also showed that this risk was low compared to the demographic profile of individuals observed in the cohort. The authors concluded that there was no evidence that PPI use led to an increase in diagnosed infections, but rather that these other factors did. The cohort in Brophy et al. [19] comprised mainly persons from our two oldest age groups (average age: 58 years), the age groups for which we estimated the effect of PPI use to be smaller compared with younger ages. Mimicking their calculation methodology by dividing our counterfactual incidence rate (i.e. no PPI prescription) among those older than 50 years by the reported rate, we obtained similar hazard ratios ranging from 1.3 to 1.7 depending on the year. In our study, it was the combination of the volume of PPI prescriptions per age group and the increased risk, albeit smaller in the elderly, that resulted in the estimated impact of PPI use on campylobacteriosis incidence at population level. In addition, the sudden trend break in 2012 at population level in the Netherlands is not easily explained completely by a change in factors related to the demographic profile of those being prescribed PPIs, as these factors are generally not as dynamic as drug use. Thus, our data do not conflict with the results from Brophy et al. [19], but support the hypothesis that PPI use results in an increased campylobacteriosis risk at population level.

The change in purchases of fresh chicken fillet during the study period, corrected or not for the prevalence of Campylobacter contamination in retail stores, was not associated with reported campylobacteriosis case numbers. However, changes in the consumption of frozen chicken were related to the increasing number of campylobacteriosis cases. No statistical correlation existed between purchases of fresh vs frozen meat at population level (data not shown), suggesting that an increase in purchases of frozen chicken was not associated with a decrease in purchase of fresh chicken fillet. Freezing of chicken fillet has been suggested to reduce contamination levels, and hence the risk of infection, in other studies [20], and this effect may also have influenced our findings. Alternatively, increases in the consumption of frozen chicken may represent a 
reduction in other risk-increasing food-related exposures, as suggested previously [5]. The fact that the consumption of fresh chicken fillet was not associated with the incidence of campylobacteriosis may be due to several factors modulate the representativeness of chicken fillet purchases as proxy for chicken fillet as risk factor. These include variations in the numbers of Campylobacter on individual fillets or changes in antigenic types that limit the protective effects of acquired immunity. Chicken fillet consumption was associated with increased campylobacteriosis risk in a previous study in the Netherlands [5].

Annual reports of the SFK are based on records for PPIs prescribed by general practitioners and physicians and dispensed by pharmacies. PPIs that are obtained over the counter in the Netherlands are not included in these reports. If the proportion obtained over the counter was negligible, or the ratio was similar in all study years, then the effect of disregarding the use of non-prescribed PPIs on our estimates was probably minimal. This proportion may, however, be sensitive to changes in refund policies of health insurance companies. For instance, refund policies changed in 2012, which is likely to have caused an abrupt decrease in PPIs prescribed at pharmacies. This may have led to an increase in over-the-counter sales, but data to examine such changes were unavailable.

In conclusion, we found a potential association between increasing PPI prescriptions and increasing campylobacteriosis incidence. The effect of PPI prescriptions on incidence was age-dependent and largest for the youngest age group, but the oldest age group contributed most to the overall incidence because they had the largest share of PPI prescriptions. In addition to the beneficial health effects of PPIs, this ecological study suggests a substantial impact of PPI use on the campylobacteriosis incidence in the Netherlands. Comparison with other countries with a different history of PPI prescriptions and campylobacteriosis trends may add to the understanding of the role of these drugs in the incidence at population level. Furthermore, a risk-benefit analysis, based on a prospective, individual-based study design, could provide insight in the net health benefit of PPI use and could inform a review of current prescription guidelines. Such a study should also include gastrointestinal pathogens other than Campylobacter spp. for which a similar effect can be expected [4]. While waiting for such results to become available, however, critical evaluation of current prescription policies is indicated. Furthermore, our study suggests that PPI users should be added to the susceptible groups targeted for specific food safety information and stresses the need for effective food safety management in the light of an increasing number of vulnerable consumers.
Acknowledgements

The authors thank Riny Janssen (RIVM) for stimulating discussions on this topic.

\section{Conflict of interest}

None declared.

\section{Authors' contributions}

WvP, MB, and AHH conceived the study and evaluated study results. MB conducted the data search and data analysis. WvP provided surveillance data. MK and MW provided data and evaluated the study results. MB drafted the first version of the manuscript and all authors contributed to its finalisation.

\section{References}

1. Schubert ML. Gastric secretion. Curr Opin Gastroenterol. 2008;24(6):659-64. http://dx.doi.org/10.1097/ MOG.obo13e328311a65f

2. de Jonge R, Ritmeester WS, van Leusden FM. Adaptive responses of Salmonella enterica serovar Typhimurium DT104 and other S. Typhimurium strains and Escherichia coli 0157 to low pH environments. J Appl Microbiol. 2003:94(4):625-32. http://dx.doi.org/10.1046/j.1365-2672.2003.01875.x

3. de Jonge R, Takumi K, Ritmeester WS, van Leusden FM. The adaptive response of Escherichia coli 0157 in an environment with changing $\mathrm{pH}$. J Appl Microbiol, 2003;94(4):555-60. http:// dx.doi.org/10.1046/j.1365-2672.2003.01865.x

4. Bavishi C, Dupont HL. Systematic review: the use of proton pump inhibitors and increased susceptibility to enteric infection. Aliment Pharmacol Ther. 2011;34(11-12):1269-81. http://dx.doi.org/10.1111/j.1365-2036.2011.04874.x

5. Doorduyn Y, Van Den Brandhof WE, Van Duynhoven YT, Breukink BJ, Wagenaar JA, Van Pelt W. Risk factors for indigenous Campylobacter jejuni and Campylobacter coli infections in The Netherlands: a case-control study. Epidemiol Inf. 2010;138(10):1391-404. http://dx.doi.org/10.1017/ So95026881000052X

6. Boysen L, Nauta M, Duarte AS, Rosenquist H. Human risk from thermotolerant Campylobacter on broiler meat in Denmark. Int J Food Microbiol. 2013;162(2):129-34. http://dx.doi. org/10.1016/j.ijfoodmicro.2013.01.009

7. Tustin J, Laberge K, Michel P, Reiersen J, Dadadottir S, Briem $\mathrm{H}$, et al. A national epidemic of campylobacteriosis in Iceland, lessons learned. Zoonoses Public Health. 2011;58(6):440-7. http://dx.doi.org/10.1111/j.1863-2378.2010.01387.x

8. Maassen C, De Jong A, Stenvers O, Valkenburgh S, Friesema I, Heimeriks K, et al. Staat van zoönosen 2011. [State of zoonotic diseases 2011]. Bilthoven: Rijksinstituut voor Volksgezondheid en Milieu (National Institute for Public Health and the Environment; RIVM); 2012. Dutch. Available from: http://www. rivm.nl/bibliotheek/rapporten/330291008.pdf

9. Personen met verstrekte geneesmiddelen; leeftijd en geslacht. [Individuals with medicines supplied; age and sex]. StatLine database. The Hague: Statistics Netherlands (CBS). [Accessed: 10 Jan 2013]. Available from: http://statline.cbs.nl/StatWeb/pu blication/?DM $=S L N L \& P A=81071 N E D \& D 1=0 \& D 2=0 \& D 3=a \& D 4=$ $6 \& D_{5}=a \& H D R=T, G 4, G 1 \& S T B=G_{3}, G 2 \& V W=T$

10. Bevolking; geslacht, leeftijd en burgerlijke staat, 1 januari. [Population; sex, age and marital status, 1 January]. StatLine database. The Hague: Statistics Netherlands (CBS). [Accessed: 10 Jan 2013]. Available from: http://statline.cbs.nl/ StatWeb/publication/?DM $=S L N L \& P A=7461 B E V \& D 1=0 \& D 2=a$ $\& D_{3}=0-100 \& D_{4}=54-62 \& H D R=T, G 3 \& S T B=G 1, G 2 \& V W=T$

11. van Pelt W, de Wit MA, Wannet WJ, Ligtvoet EJ, Widdowson MA, van Duynhoven YT. Laboratory surveillance of bacterial gastroenteric pathogens in The Netherlands, 1991-2001. Epidemiol Inf. 2003;130(3):431-41.

12. Mathers CD, Vos T, Lopez AD, Salomon J, Ezzati M, editors National burden of disease studies: a practical guide. Edition 2.o. Global Program on Evidence for Health Policy. Geneva: World Health Organization; 2001. Available from: http://www. who.int/healthinfo/nationalburdenofdiseasemanual.pdf

13. Rothman KJ, Greenland S, Lash TL. Modern epidemiology. 3rd ed. Philadelphia: Lippincott Williams \& Wilkins; 2008. 
14. Feldman M, Cryer B, McArthur KE, Huet BA, Lee E. Effects of aging and gastritis on gastric acid and pepsin secretion in humans: A prospective study. Gastroenterol. 1996;110(4):104352. http://dx.doi.org/10.1053/gast.1996.v110.pm8612992

15. Hurwitz A, Brady DA, Schaal SE, Samloff IM, Dedon J, Ruhl CE. Gastric acidity in older adults. JAMA. 1997;278(8):659-62. http://dx.doi.org/10.1001/jama.1997.03550080069041

16. Russell TL, Berardi RR, Barnett JL, Dermentzoglou LC, Jarvenpaa KM, Schmaltz SP, et al. Upper gastrointestinal $\mathrm{pH}$ in seventy-nine healthy, elderly, North American men and women. Pharm Res. 1993;10(2):187-96. http://dx.doi. org/10.1023/A:1018970323716

17. Takumi K, de Jonge R, Havelaar A. Modelling inactivation of Escherichia coli by low pH: application to passage through the stomach of young and elderly people. J Appl Microbiol. 2000;89(6):935-43. http://dx.doi. org/10.1046/j.1365-2672.2000.01193.x

18. Strachan NJ, Rotariu O, Macrae M, Sheppard SK, Smith-Palmer A, Cowden J, et al. Operationalising factors that explain the emergence of infectious diseases: a case study of the human campylobacteriosis epidemic. PloS One. 2013;8(11):e79331. http://dx.doi.org/10.1371/journal.pone.0079331

19. Brophy S, Jones KH, Rahman MA, Zhou SM, John A, Atkinson $M D$, et al. Incidence of campylobacter and salmonella infections following first prescription for PPI: A cohort study using routine data. Am J Gastroenterol. 2013;108(7):1094-100. http://dx.doi.org/10.1038/ajg.2013.30

20. Rosenquist H, Sommer HM, Nielsen NL, Christensen BB. The effect of slaughter operations on the contamination of chicken carcasses with thermotolerant Campylobacter. Int J Food Microbiol. 2006;108(2):226-32. http://dx.doi.org/10.1016/j. ijfoodmicro.2005.12.007 